NBER WORKING PAPER SERIES

\title{
EARNINGS EXPECTATIONS IN THE COVID CRISIS
}

\author{
Augustin Landier \\ David Thesmar \\ Working Paper 27160 \\ http://www.nber.org/papers/w27160
}

\section{NATIONAL BUREAU OF ECONOMIC RESEARCH 1050 Massachusetts Avenue Cambridge, MA 02138}

May 2020

We thank Hector Chan, Hui Chen, Hugues Langlois and Eben Lazarus, as well as seminar participants at MIT, for discussions \& feedback. The views expressed herein are those of the authors and do not necessarily reflect the views of the National Bureau of Economic Research.

At least one co-author has disclosed a financial relationship of potential relevance for this research. Further information is available online at http://www.nber.org/papers/w27160.ack

NBER working papers are circulated for discussion and comment purposes. They have not been peerreviewed or been subject to the review by the NBER Board of Directors that accompanies official NBER publications.

(C) 2020 by Augustin Landier and David Thesmar. All rights reserved. Short sections of text, not to exceed two paragraphs, may be quoted without explicit permission provided that full credit, including (C) notice, is given to the source. 
Earnings Expectations in the COVID Crisis

Augustin Landier and David Thesmar

NBER Working Paper No. 27160

May 2020

JEL No. G01,G32,G4

\begin{abstract}
$\underline{\text { ABSTRACT }}$
We analyze firm-level analyst forecasts during the COVID crisis. First, we describe expectations dynamics about future corporate earnings. Downward revisions have been sharp, mostly focused on 2020, 2021 and 2022, but much less drastic than the lower bound estimated by Gormsen and Koijen (2020). Analyst forecasts do not exhibit evidence of over-reaction: As of mid-May, forecasts over 2020 earnings have progressively been reduced by $16 \%$. Longer-run forecasts, as well as expected "Long-Term Growth" have reacted much less than short-run forecasts, and feature less disagreement. Second, we ask how much discount rate changes explain market dynamics, in an exercise similar to Shiller (1981). Given forecast revisions and price movements, we estimate an implicit discount rate going from $10 \%$ in mid-February, to $13 \%$ at the end of March, back down to their initial level in mid-May. We then decompose discount rate changes into three factors: changes in unlevered asset risk premium $(0 \%)$, increased leverage $(+1 \%)$ and interest rate reduction (-1\%). Overall, analyst forecast revisions explain all of the decrease in equity values between January 2020 and mid May 2020, but they do not explain shorter term movements.
\end{abstract}

\author{
Augustin Landier \\ HEC Paris \\ 1 rue de la libération \\ 78351 Jouy en Josas Cedex \\ France \\ augustin.landier@tse-fr.eu \\ David Thesmar \\ MIT Sloan School of Management \\ 100 Main Street, E62-632 \\ Cambridge, MA 02142 \\ and NBER \\ thesmar@mit.edu
}




\title{
Earnings Expectations in the COVID Crisis*
}

\author{
Augustin Landier ${ }^{\dagger} \quad$ David Thesmar ${ }^{\ddagger}$ \\ This draft: May 13, 2020 \\ First draft: April 27, 2020
}

\begin{abstract}
We analyze firm-level analyst forecasts during the COVID crisis. First, we describe expectations dynamics about future corporate earnings. Downward revisions have been sharp, mostly focused on 2020, 2021 and 2022, but much less drastic than the lower bound estimated by Gormsen and Koijen (2020). Analyst forecasts do not exhibit evidence of over-reaction: As of mid-May, forecasts over 2020 earnings have progressively been reduced by $16 \%$. Longerrun forecasts, as well as expected "Long-Term Growth" have reacted much less than short-run forecasts, and feature less disagreement. Second, we ask how much discount rate changes explain market dynamics, in an exercise similar to Shiller (1981). Given forecast revisions and price movements, we estimate an implicit discount rate going from $10 \%$ in mid-February, to $13 \%$ at the end of March, back down to their initial level in mid-May. We then decompose discount rate changes into three factors: changes in unlevered asset risk premium $(0 \%)$, increased leverage $(+1 \%)$ and interest rate reduction $(-1 \%)$. Overall, analyst forecast revisions explain all of the decrease in equity values between January 2020 and mid May 2020, but they do not explain shorter term movements.
\end{abstract}

\section{Introduction}

The stock-market market has fallen dramatically as a result of fears about the economic impact of COVID-19. Gormsen and Koijen (2020) use dividend strips to infer the shift in the term structure of expectations of future dividends. We propose instead to directly look at revisions of analyst forecasts using IBES. There are advantages and disadvantages to both methods: Using prices

*We thank Hector Chan, Hui Chen, Hugues Langlois and Eben Lazarus, as well as seminar participants at MIT, for discussions \& feedback.

${ }^{\dagger} \mathrm{HEC}$ Paris

${ }_{\ddagger}^{\ddagger}$ MIT Sloan, NBER and CEPR 
of dividend futures has the advantage of offering an analysis purely based on prices, which are more likely to reflect investors' beliefs. However, it forces to focus on the aggregate and only provides a lower bound to changes in forecasts as shocks to risk-premia are not directly observed. Using analyst forecasts allows for a firm-level analysis and a direct measure of revisions in beliefs. However, to connect it to stock-prices, we need to assume that analyst forecasts are a reliable proxy for investors' beliefs.

Our work is part of a fast growing set of papers looking at how the stock-market has reacted to the COVID outbreak. Gormsen and Koijen (2020) provides lower bound on the change in expected aggregate S\&P500 dividends. Ramelli and Wagner (2020) and Ding et al. (2020) study in detail how firm-level characteristics such as leverage, cash-holdings, supply-chain and industry affect the cross-section of returns. Alfaro et al. (2020) show how unanticipated changes in predicted infections forecast aggregate equity market returns. Albuquerque et al. (2020) find a positive correlation between ESG ratings and abnormal returns through the crisis.

We address two main issues that speak to the finance literature. First we show how the term structure of earnings expectations has shifted over the course of March, April and May 2020. Downward revision has occurred smoothly, but was mostly focused on 2020-2022 - longer-term forecasts have remained quite stable. Analyst forecast dispersion has mostly increased for shortterm horizons. The smooth reaction of short-term forecasts, and the rather muted response of long-term forecasts, paints a picture that is somewhat unusual when compared to the available literature on expectations and stock returns. This literature indeed shows that (1) short term EPS forecasts of analysts tend to underreact to news (Bouchaud et al. (2019), Ma et al. (2020)) while (2) long-term growth expectations overreact (Bordalo et al. (2018)). The fact that long-term forecasts have reacted less (actually, not significantly so, beyond 2023) than short-term forecasts might reflect the intrinsic short-term nature of the shock.

Second, using stock prices, we back out the implied change over time in the discount rate for each firm. If discount rates had not changed, by May 11, the decline in stock prices implied by forecast revisionsis very close to realized returns (we compute unweighted returns in this paper). We show that discount rate shocks are the main driver of the V-shaped evolution of stock-prices, but, by mid May 2020, revisions were such that valuations were consistent with a discount rate of about $10 \%$, the same one as mid-February. This exercise is related to the large literature on discount rates movements that was initiated by Shiller (1981). The difference between his analysis and ours is twofold. First, we use forecasts of future cash-flows instead of ex post dividend realizations or model-predicted growth. Second, we decompose the increase in discount rate into three terms: (1) interest rates, (2) unlevered asset risk premium and (3) the leverage effect (declining stock prices lead to an increase in expected equity returns). We find that the leverage effect is large: it contributes 2 ppt to the increase in discount rate at the end of march, and $1 \mathrm{ppt}$ in mid 
May after the market rebound. Overall, our decomposition suggests that the unlevered asset risk premium has returned to its mid-February level by mid-May, so that (1) the increase in equity premium is fully accounted for by the leverage effect and (2) it is fully offset by the 1ppt reduction in interest rates. Last, we document that the sensitivity of cumulative returns to discount rates is rather low in the cross-section of stocks. This suggests that the term structure of equity discount rates is not flat, and that stock prices, combined with earnings forecasts, can be used to identify it. This also suggests that non-flat equity risk premium term structure should be an important component of firm valuation models (Ang and Liu (2004)).

Section 2 presents the data. Section 3 analyzes analyst revisions. Section 4 connects forecast revisions and returns. It also infers discount rates, decomposes them into leverage effect, risk premium and interest rate. It also evaluates the sensitivity of returns to discount rate changes. Finally, Section 5 concludes.

\section{Data}

Using CRSP (via WRDS), we select firms, which at the end of 2019 are traded on NYSE, Nasdaq or Amex. Among them, we then retain the top 1000 by total market capitalization as of December 31, 2019. This gives us a list of Cusip identifiers, which we use to retrieve historical returns and IBES forecasts through a Refinitiv-Eikon platform (Thomson-Reuters). We use Refinitiv to have up-to-date forecasts and stock returns, which are not yet available on WRDS. We focus on forecasts issued up until May, 112020 about Earnings per Share (EPS) for fiscal years 2020, 2021, 2022, 2023, 2024. We use forecasts averaged across analysts (i.e. the consensus forecast), as updated on the Eikon platform on a daily basis. We also download Long-term growth forecasts (variable LTG), providing expected annual growth in operating earnings over the next full business cycle. We use market betas computed as of December 31, 2019, based on one year of daily returns. Data on fundamentals (debt, total assets, GIC sector) are retrieved from Compustat.

To give a sense of the data, we reproduce in Figure 1 the evolution of average EPS forecasts for two large firms, Facebook and Ford. We show forecasts at five horizons $(2020, \ldots, 2024)$. We show how these forecasts have evolved over time. First, we see that long-term expectations did not react as much as short-term expectations. Second, forecast revisions differ across firms in expected ways: small impact in the case of Facebook, while revisions of Ford's earnings are strongly negative, even for 2023 . 
Figure 1: Forecast Revisions - Two Examples

This figure shows the Evolution of average forecasts of annual earnings per share for Ford and Facebook between February 15, 2020 and May 11, 2020. We report forecasts for fiscal years 2020, ..., 2024. IBES forecasts are retrieved through Refinitiv-Eikon's platform (Thomson-Reuters).
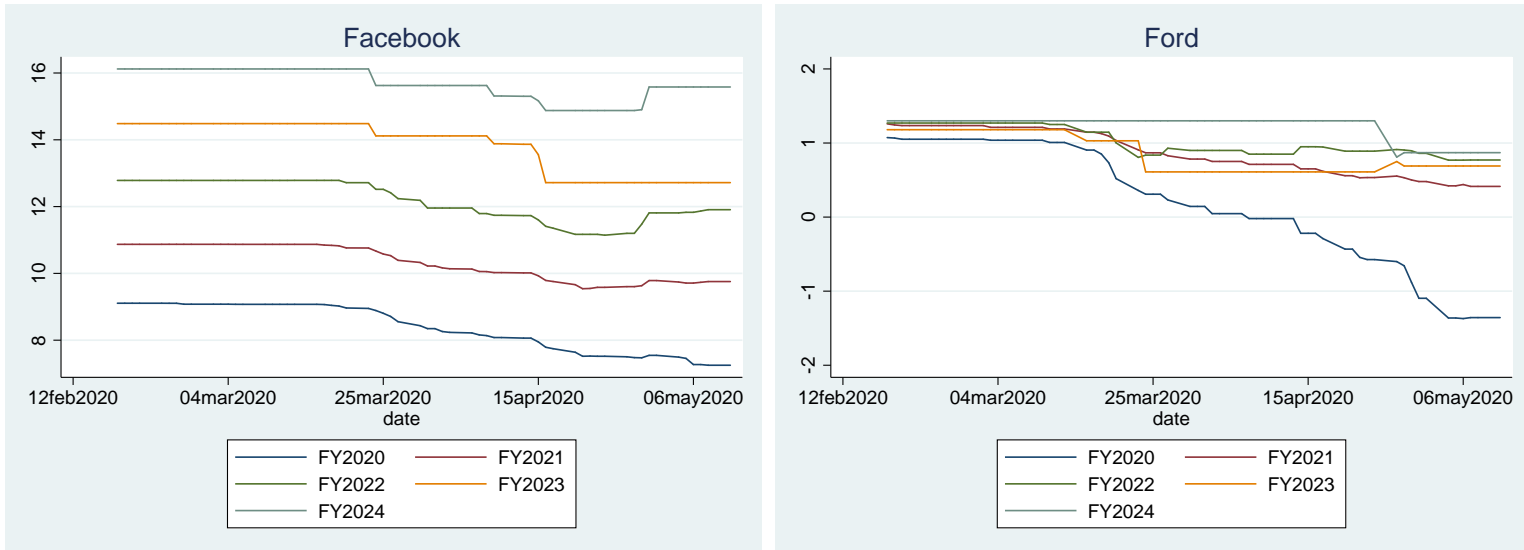

\section{Change in the Term Structure of Expectations}

\subsection{Term Structure of Implied Growth Forecasts}

For each firm $i$ at date $t$ which has positive earnings in 2019, we compute the implicit annualized growth at horizon $h$ as:

$$
g_{i, t, h}=\frac{1}{h-2019}\left(\frac{F_{t} E P S_{i, h}-E P S_{i, 2019}}{E P S_{i, 2019}}\right)
$$

This linearized growth formula allows to accommodate for negative future $F_{t} E P S_{i, h}$, of which there are many in particular during the COVID-19 crisis. To be in line with analyst forecasts ${ }^{1}$, we use realized earnings as reported by IBES for $E P S_{i, 2019}$.

In Figure 2 we report the median implicit growth across all firms per horizon. We compute the median of this implicit growth measure across firms, for each date $t$ and each horizon. We see that:

- 2020 EPS growth expectations were slashed from $12 \%$ down to nearly $-6 \%$, or a $16 \%$ reduction.

- Longer-term growth expectations were reduced but to a much lesser extent. 2024 forecasts decreased from $13 \%$ annually to $10.2 \%$.

\footnotetext{
${ }^{1}$ IBES forecasts typically are about "street earnings" rather than GAAP earnings (reported in e.g. Compustat). See Abarbanell and Lehavy (2007).
} 
This confirms the preliminary insights we gained from Figure 1. The bottom line is that analysts have strongly reduced their forecasts, even for 2023.

Figure 2: Forecasted Annualized Growth of Earnings

This figure shows the Evolution of implicit annualized growth at horizons 2020, .., 2024. For every day $t$ between February 15,2020 and May 11, 2020, we define annualized growth expected at time $t$ for firm $i$ at horizon $h$ as $g_{i, t, h}=\frac{1}{h-2019}\left(\frac{F_{t} E P S_{i, h}-E P S_{i, 2019}}{E P S_{i, 2019}}\right)$, where $F_{t} E P S_{i, h}$ is the average forecast at date $t$ of annual earnings per share for firm $i$ and horizon $h$. We restrict the sample to firms with a positive realized EPS in $2019\left(E P S_{i, 2019}>0\right)$ and report a cross-sectional median at each date $t$.

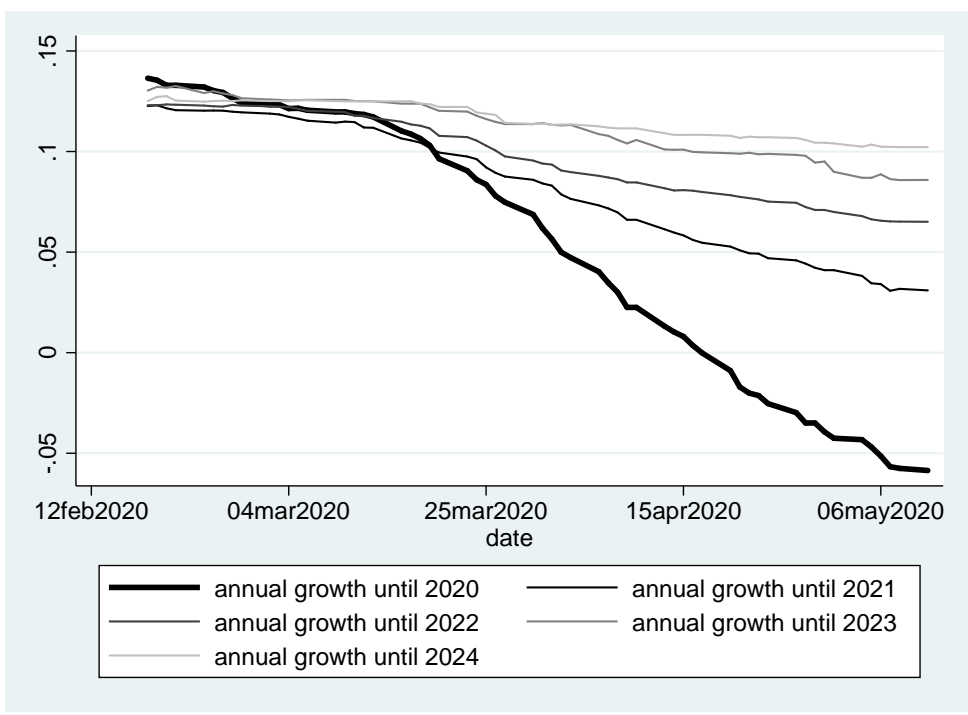

We then present again the above evidence in a different way, by looking at the term structure of expectations of growth for two separate dates. In Figure 3, we plot the annualized growth rates $g_{i, t, h}$ per horizon $h$ for just two dates. This is essentially the same information as in Figure 2, except that we show it only for two dates, and now report confidence bands. ${ }^{2}$ Consistent with Figure 2, we find that forecasts have been revised downwards for 2020 (to slightly negative growth). Analysts anticipate the COVID19 shock to last well into 2022. By 2023-2024, they expect the economy to have returned to trend.

\subsection{Disagreement among Analysts}

IBES reports the standard deviation of earnings forecasts (across analysts) at the different horizons, $\sigma_{i, t, h}$. This is a measure of disagreement among analysts and can be interpreted as reflecting

\footnotetext{
${ }^{2}$ To be able to report confidence bands in a simple way, we trim the sample by removing observations 5 interquartile range away from the median. On the chart, we report the mean (which after trimming does not differ much from the median) and the confidence band as two times the standard error divided by the square root of the number of observations.
} 
Figure 3: Term Structure of Expected Earnings Growth

Before and After Readjustment

This figure shows the annualized growth rates $g_{i, t, h}$ per horizon $h$ for two dates (February 15, 2020 and May 11, 2020), averaged across our sample of firms. We trim the sample by removing observations 5 interquartile range away from the median. Confidence bands are computed as twice the standard error divided by the square root of the number of observations.

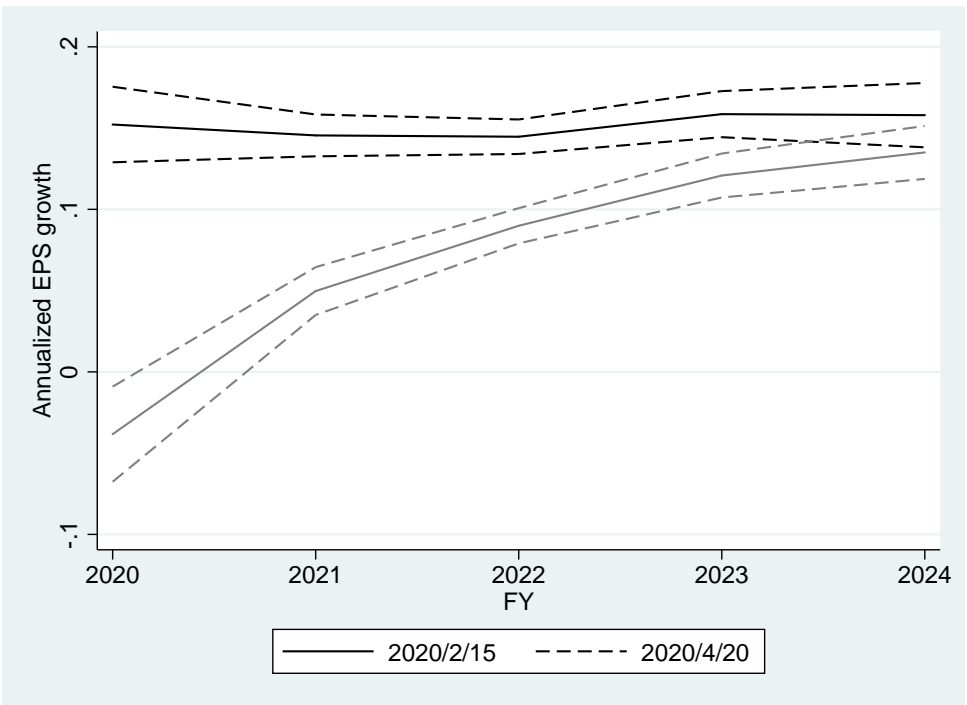

the level of economic uncertainty. We normalize this dispersion by dividing it by past realized earnings $\left(E P S_{i, 2019}\right)$ when they are positive. In Figure 4, we plot the median normalized disagreement per horizon among firms in our sample. We observe a sharp increase in disagreement. Interestingly, this increase is, until mid-April, stronger at shorter horizon, so that the term-structure of disagreement is flipped-over: There is now more disagreement about short horizons than long horizons, contrary to the pre-crisis period. Note that after April 15, we observe decreasing disagreement about 2020 Earnings, reflecting the fact that Quarter 1 Earnings for 2020 are being published, mechanically limiting uncertainty to the subsequent three quarters.

\subsection{Analyst Biases}

\subsubsection{Optimism}

The financial literature documents a positive bias in analyst forecasts (Dreman and Berry (1995)). This upward bias can be partly explained by conflicts of interest (see e.g. Michaely and Womack (1999), Dechow et al. (2000), Hong and Kubik (2003), Cowen et al. (2006)). It is tempting to shrink analysts forecasts by an amount corresponding to the average bias, such as to use a more objective forecast; However, while trying to do so, we found evidence that the upward bias of analysts has been strongly reduced after the burst of the internet bubble: In Figure A.1, we computed for 
Figure 4: Dispersion of Forecasts

This figure plots the standard deviation of yearly earnings forecasts (across analysts) at different fiscal year horizons, normalized by 2019 realized earnings $\left(E P S_{i, 2019}\right)$. We restrict to firms with $E P S_{i, 2019}>0$ and report the median of this normalized dispersion for each date.

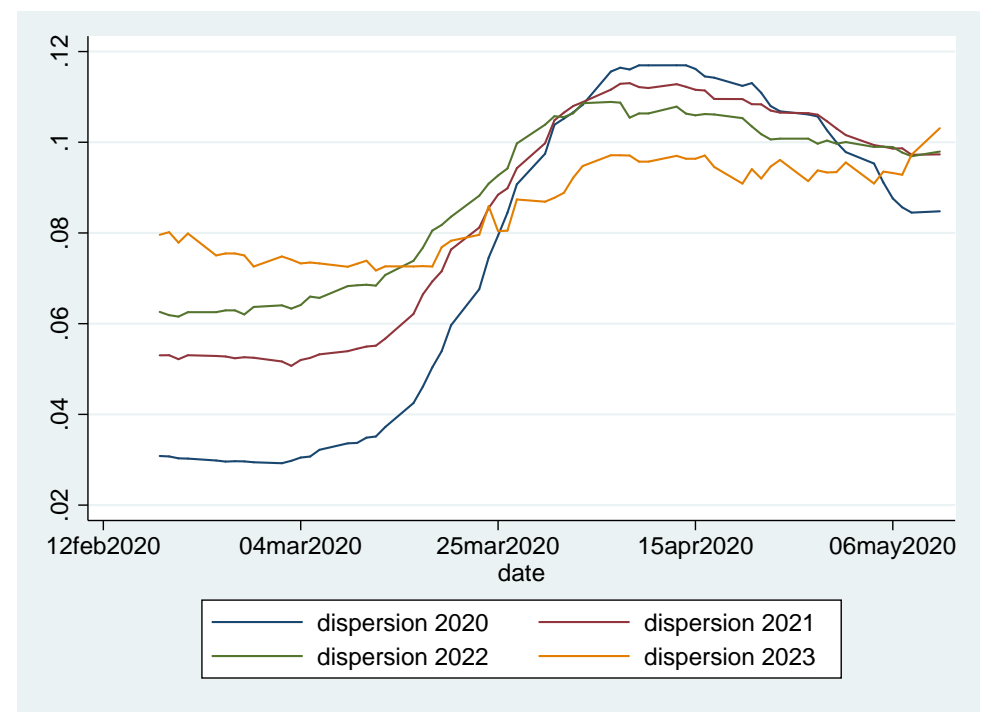

each year the average normalized difference between forecasted and realized earnings. While this difference was strongly positive in the 90s, it has become quite close from zero, especially for horizons of 1 and 2 years. This is in line with the view that regulations of sell-side research introduced after the 2001 have reduced incentives for analysts to provide rosy views on companies (Kadan et al. (2008)). It might also be related to an increased reliance of earnings guidance by companies. We also investigated specifically analysts forecasts during the financial crisis, which is the closest acute crisis episode: We observe in Figure A.2 drastic downward adjustments by analysts after the Lehmann Bankruptcy, suggesting that conditional on updating, analysts do not hesitate to slash their forecasts substantially ${ }^{3}$. However, Figure A.2 also suggests that these adjustments can be quite sluggish, raising the question of under-reaction, rather than optimism.

\subsubsection{Over-reaction and Under-reaction}

An old debate in the behavioral literature is whether stock analysts under-react or over-react to news. Lakonishok et al. (1994), DeBondt and Thaler (1990), Laporta (1996) and Bordalo et al. (2018) document extrapolative bias by analysts about glamor stocks. Abarbanell and Bernard (1992) and Bouchaud et al. (2019) find evidence that analysts actually under-react, leading to serial auto-correlation in revisions and predictability in forecast errors. The evidence so far in this

\footnotetext{
${ }^{3}$ In a more general study of analysts forecasts in bad times, Loh and Stulz (2018) document that conditional on a crisis, analysts are quite active in producing relevant information: forecast errors per unit of uncertainty fall, and analyst publish more frequent and longer reports.
} 
paper shows that analyst consensus forecast is updated downward in a smooth manner, which contrasts with the volatility of prices (see next section). This is interesting as over-reaction is often associated to contexts of salient news, which the COVID crisis belongs to (See Ramelli and Wagner (2020) for information on the spike of attention to COVID).

The evidence that beliefs dynamics during the COVID crisis has been sluggish also applies to the "Long Term Growth" (LTG) updates by analysts: This IBES variable, which corresponds to average growth over the coming business cycle, is used in Laporta (1996) and Bordalo et al. (2018). Figure 5 shows the evolution of median LTG ("Long term growth") in our sample. We restrict ourselves to firms for which an LTG is continuously present in the data.

Figure 5: Long-Term Growth

This figure plots the the evolution of the LTG forecast ("Long term growth") over time in our sample. We report the median (in \%) across all firms of the consensus LTG forecast reported by IBES (which is an average across analysts for each firm).

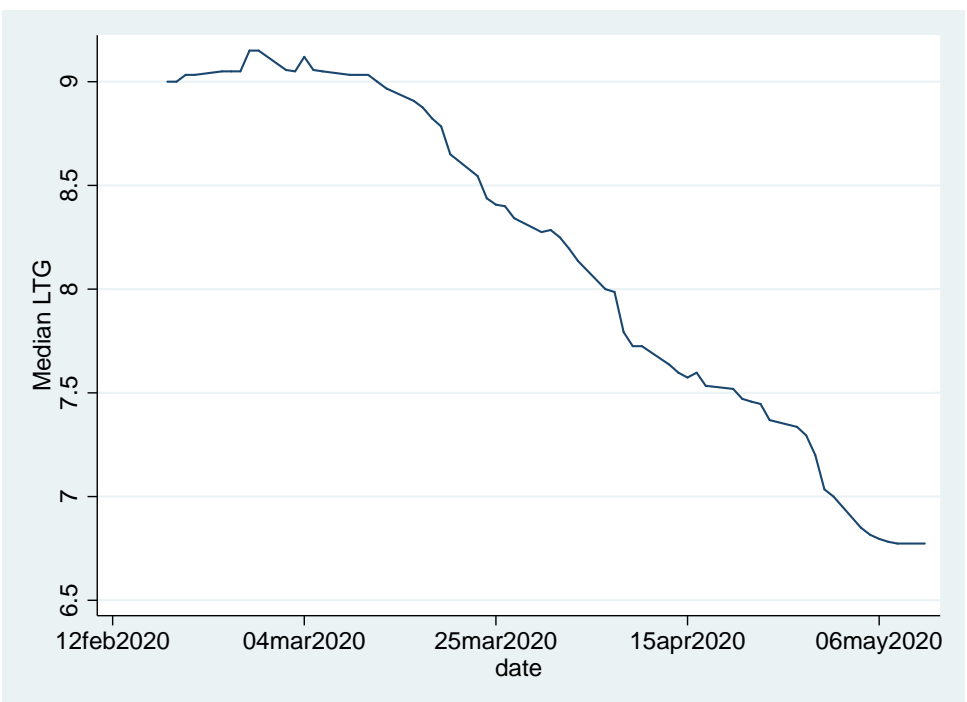

Evidence from Figure 5 is consistent with evidence from the term structure of forecasts. Expectations for 2024 suggest a reduction in expected EPS growth until 2024 by about 1.5 ppt (see Figure 3 for instance). Evidence from revisions in LTG does suggest a reduction of the same amount.

\subsection{Revisions across Industries}

We highlight cross-industry dispersion if the COVID shock by showing how much forecasts at different horizons have been revised in each sector. We divide our sample of 1000 firms into GIC sectors and show the median value of $\left(\frac{F_{T_{1}} E P S_{i, h}}{F_{T_{0}} E P S_{i, h}}-1\right)$ where $T_{1}$ is May 11, 2020 and $T_{0}$ is February 15, 2020. In Figure 6, we report the industry breakdown. Each bar represents the \% 
change in typical forecast of yearly EPS in a given industry for varions horizons. The different bars allow to evaluate the relative persistence of the COVID shock across industries: Real estate faces the strongest downward revision but only at short horizon. Utilities and Consumer Staples are the sectors that are the least hit by the crisis, both in the short-term and the medium-term. Some industries such as Consumer Discretionary face a very persistent shock (the revision in their forecasted earnings is similar for 2020,2021,2022). Interestingly, the crisis has led to downward revisions that are still visible at 4 years horizon: Analysts downgrade significantly their initial forecasts even for 2023.

Figure 6: Revision by Industries

This figure represents the median $\%$ change in EPS forecasts $\left(\frac{F_{T_{1}} E P S_{i, h}}{F_{T_{0}} E P S_{i, h}}-1\right)$ by industry (GIC sectors). The final date (T $)$ is May 11, 2020 and the start date $\left(T_{0}\right)$ is February 15, 2020. We restrict our sample to firms with $F_{T_{0}} E P S_{i, h}>0$. For each sector, we report forecasts for four horizons $h$, namely fiscal years $2020, \ldots, 2023$.

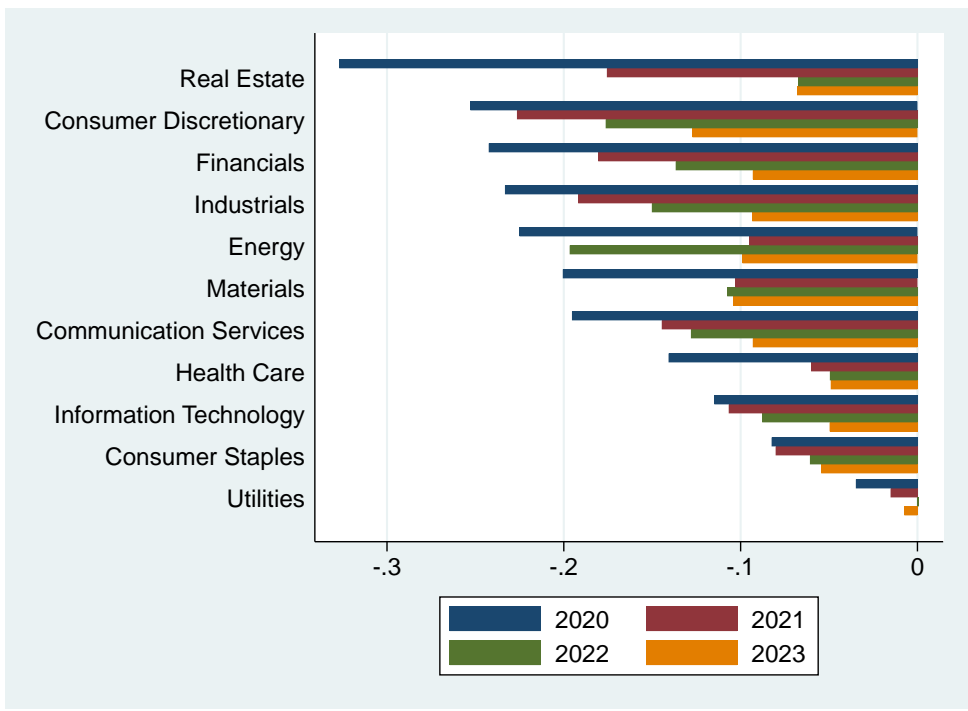

\subsection{Revisions and Firm Leverage}

The impact that a given cash-flow shock has on earnings should be larger for highly levered companies. This is simply because debt interest are a larger fraction of total cash flows for these companies, hence making earnings more sensitive to the shock. We test whether analysts do indeed anticipate a sharper reduction of earnings for high leverage companies. To do this, we sort companies in five leverage quintiles, using their market leverage as observed on December 31, 2019. We use the total book value of debt from Compustat and market capitalization from CRSP. For each date $t$, we compute $\left(\frac{F_{t} E P S_{i, h}}{F_{T_{0}} E P S_{i, h}}-1\right)$ where $T_{0}$ is February 15, and plot the median by (date, quintile of leverage) in Figure 7. This figure shows that downward revisions by analysts are 
much stronger for highly levered companies. For 2020 earnings, companies in the highest leverage quintile experiences a $-27 \%$ downward revision as of May 11, vs. $-8 \%$ for the lowest quintile of leverage. For 2021 earnings, we also observe a large spread of $-21 \%$ for the high leverage quintile vs. $-11 \%$ for the low leverage quintile.

Figure 7: Revision by Leverage Quintiles

This figure represents the median $\%$ revision in forecasts $\left(\frac{F_{t} E P S_{i, h}}{F_{T_{0}} E P S_{i, h}}-1\right)$ by quintile of leverage. The reference date $\left(T_{0}\right)$ for initial forecasts is February 15. We use market leverage computed with total debt from Compustat (for fiscal year 2019) and market capitalization from CRSP as of end of 2019. For each date, we plot the median by quintile of leverage. The sample is restricted to firms with $F_{T_{0}} E P S_{i, h}>0$.

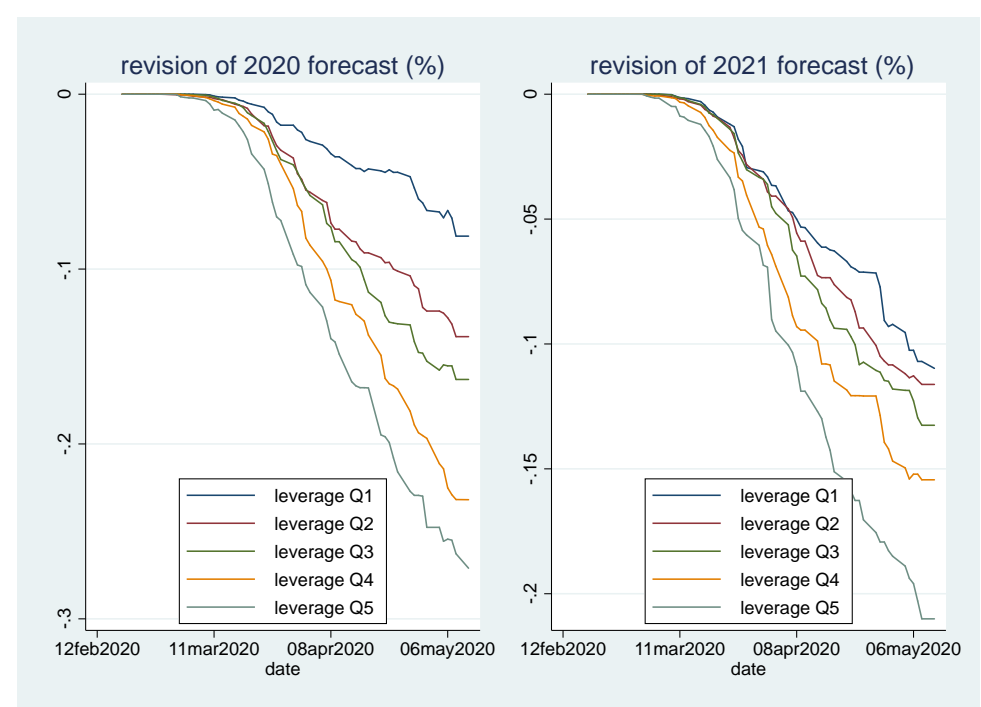

\section{Forecasts and Market Prices}

\subsection{Forecast-implied Prices vs Realized Prices}

We now conduct an exercise similar to Shiller (1981) except that we use EPS forecast revisions instead of ex post dividend realizations. We investigate the link between forecast revisions and stock returns. As a motivating fact, we show in Figure 8 the strong positive relationship between sector-level revisions in forecasts and cumulative returns over the same period.

This suggests to directly analyze the link between changes in equity valuations and changes in earnings forecasts. Specifically, for each firm-date we compute:

$$
P V_{i t}=\frac{F_{t} E P S_{2020, i}}{1+r_{i}}+\frac{F_{t} E P S_{2021, i}}{\left(1+r_{i}\right)^{2}}+\frac{F_{t} E P S_{2022, i}}{\left(1+r_{i}\right)^{3}}+\frac{\left(1+g_{i}\right) F_{t} E P S_{2022, i}}{\left(r_{i}-g_{i}\right)\left(1+r_{i}\right)^{3}}
$$

In Figure 9, we compute the mean cumulative PV growth across firms, and plot it alongside 
Figure 8: Cumulative Returns and Forecast Revisions by Industries

Each dot represents a different GIC sector. On the vertical axis is the average cumulative returns at the industry level over time-period $\left[T_{0}, T_{1}\right]$. On the horizontal axis is the mean of $\left(\frac{F_{T_{1}} E P S_{i, h}}{F_{T_{0}} E P S_{i, h}}-1\right)$. The final date $T_{1}$ is May 11, 2020 and initial date $T_{0}$ is February 15 , 2020. The sample is restricted to firms with $F_{T_{0}} E P S_{i, h}>0$.

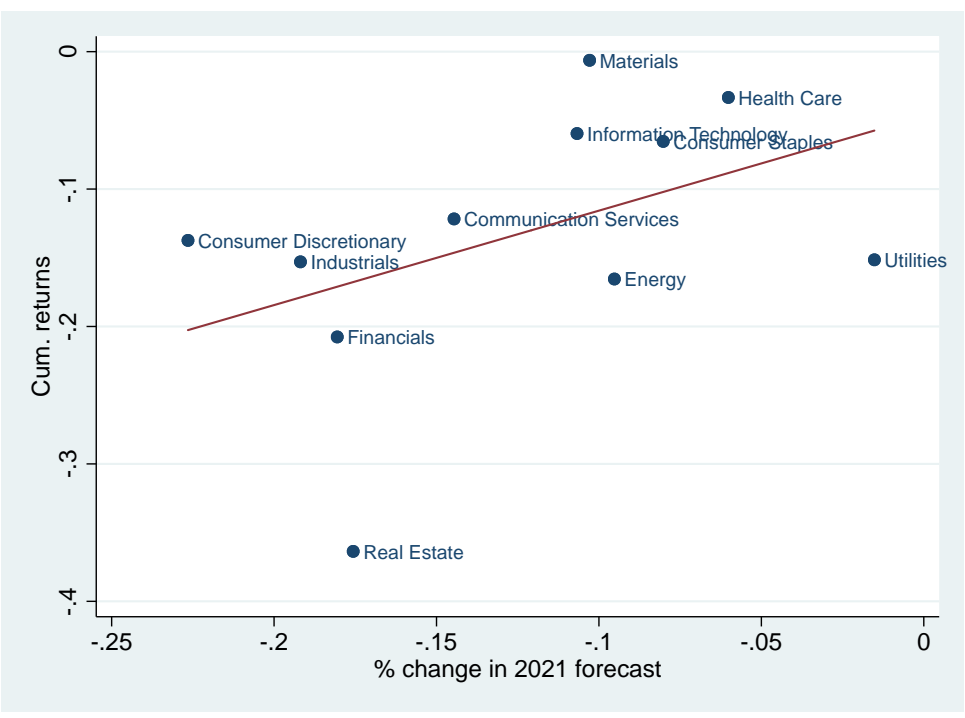

unweighted average cumulative returns (after trimming outliers). We assume $g_{i}$ is the average sales growth rate at GICS industry level over 2015-2019. For each GICS sector, we compute the average firm sales growth over 2015-2019, weighted by 2015 sales, after removing outliers. Because of this cleaning procedure, such industry growth is well behaved, goes from $0.2 \%$ to $10 \%$, with an average of $3.5 \%$. We estimate $r_{i}$ separately for each firm by imposing that $P V_{i T_{0}}=P_{i T_{0}}$, at the first date of the graph: This condition gives us one value of $r_{i}$ per firm, which is the implicit discount rate in prices. Values of $r_{i}$ above $30 \%$ are excluded. We show the distribution of discount rates in Appendix Figure A.3.

We focus on 890 firms for which $P V_{i t}$ is continuously defined throughout the period. Forecastimplied returns are down $9 \%$ since mid February while the (unweighted) average cumulative return is down $20 \%$ since the same date. Put differently, the term structure of forecast shown above is broadly consistent with half of the fall in the stock market on the entire period, but suggest a large temporary increase in discount rates during that period.

The forecast-implied estimate of $-12 \%$ is robust to the choice of growth $g_{i}$ or discount rate $r_{i}$. In Appendix Figures A.4-A.5, we compute the implied cumulative return taking alternative values of $r_{i}$ and $g_{i}$. For simplicity, we assume in this robustness check only one discount rate for all firms, so these figures should be interested as informative about elasticities, not level. 
Figure 9: Forecast Implied Returns vs Realized Returns

Assuming a constant (over time) firm-level discount rate

We report together (1) the realized cumulative return and (2) the forecast-implied cumulative return $\left(P V_{i t} / P V_{i T_{0}}-1\right)$. The forecast implied cumulative return is based on the evolution of Present Values $\left(P V_{i t}\right)$ defined above. The computation of $P V_{i t}$ uses firm-level average forecasts at date $t$ and a constant discount rate implied by the initial value of each firm at $T_{0}$. Valuations are performed at the firm level. The start date $\left(T_{0}\right)$ is February 15, 2020. We focus on 890 firms for which $P V_{i t}$ is continuously defined throughout the period.

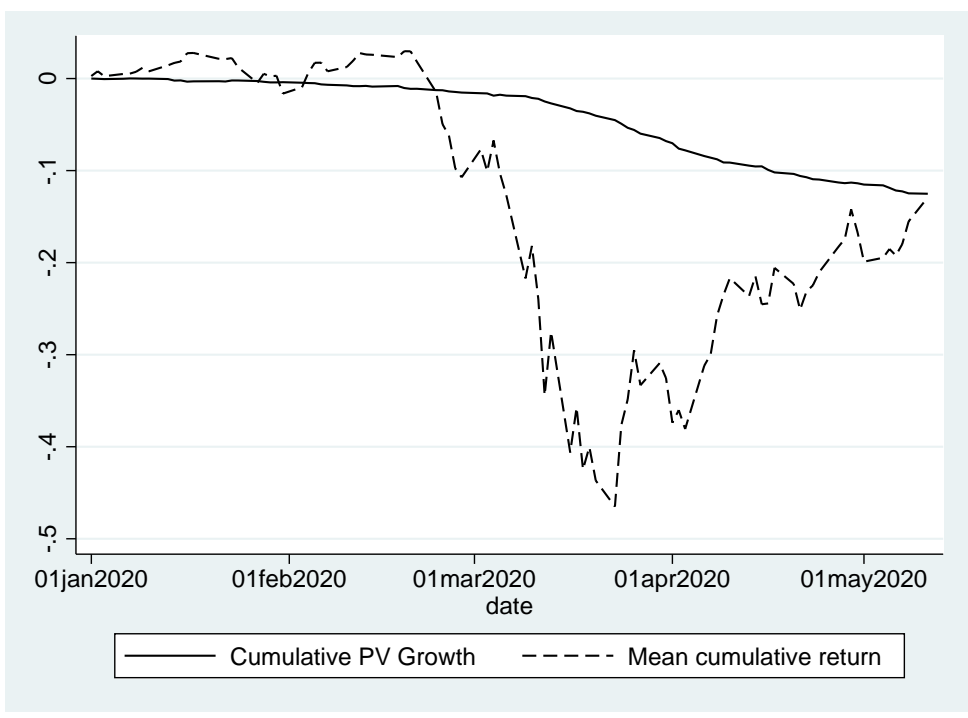

\subsection{Discount Rates}

We now provide an alternative presentation of Figure 9 where we compute the implicit firm discount rate in market valuation at each point in time. Namely, for each firm $i$ at date $t$ we compute the internal rate of return of buying one stock, which is the $r_{i t}$ that solves:

$$
P_{i t}=\frac{F_{t} E P S_{2020, i}}{1+r_{i t}}+\frac{F_{t} E P S_{2021, i}}{\left(1+r_{i t}\right)^{2}}+\frac{F_{t} E P S_{2022, i}}{\left(1+r_{i t}\right)^{3}}+\frac{\left(1+g_{i}\right) F_{t} E P S_{2022, i}}{\left(r_{i t}-g_{i}\right)\left(1+r_{i t}\right)^{3}}
$$

We set $g_{i}$, as before, as the long-term growth rate at the industry level: We assume it is not changed by the crisis. Note that by definition, $r_{i t}=r_{i}$, where $r_{i}$ is the discount rate used in Equation (1). We solve equation (2) for each firm-year observation since mid February for which all 3 forecasts and the price is available. This gives us a panel of discount rates which is the mirror image of the difference between forecast-implied valuation and market valuation.

We show the mean in Figure 10. The discount rate on stocks increases to 13\%, down to about $10 \%$, very close to its pre crisis level. This is consistent with the idea that fiscal and monetary policy announcements managed to reduce the risk premium.

To understand the dynamics of the IRR, we propose a simple decomposition which disentangles three distinct effects: (1) changes in the risk-free rate, (2) the leverage effect and (3) changes in economic risk-premia. 
Figure 10: Implicit Discount Rates

This figure plots the evolution of the mean discount rate on stocks (computed as described above), jointly with the realized average stock-return from firms in our sample.

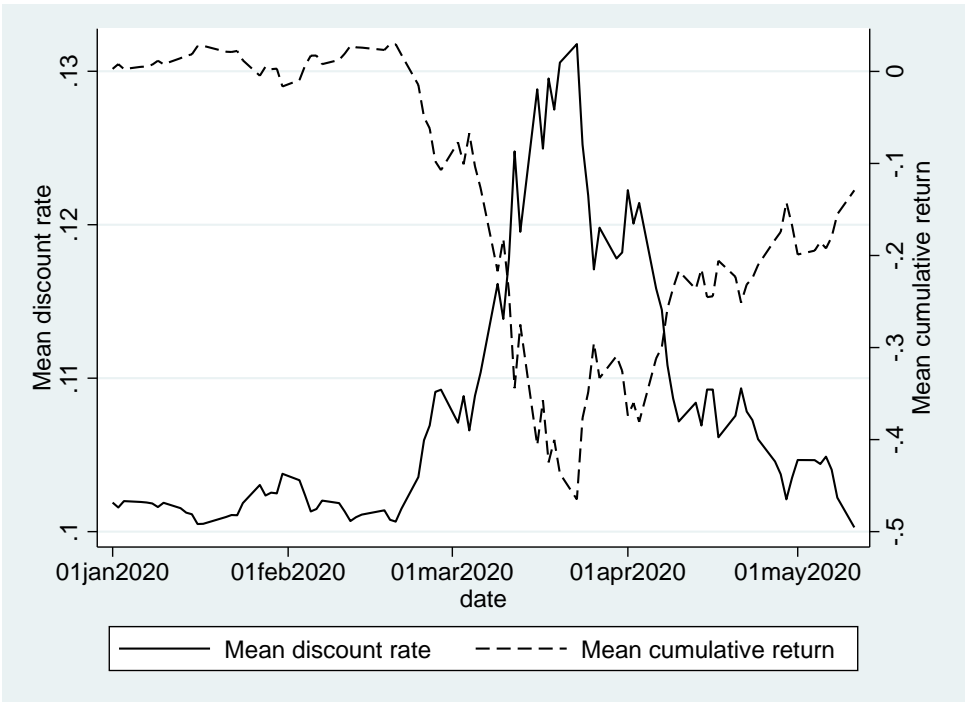

To get to this decomposition, we write the change of $I R R$ between time 0 and time $t$ as:

$$
I R R_{i t}-I R R_{i 0}=\underbrace{\left(r_{t}^{f}-r_{0}^{f}\right)}_{\text {risk-free rate effect }}+\underbrace{\left(1-\frac{l_{i 0}}{l_{i t}}\right)\left(I R R_{i t}-r_{t}^{f}\right)}_{\text {leverage effect }}+\underbrace{\frac{l_{i 0}}{l_{t}}\left(I R R_{i t}-r_{t}^{f}\right)-\left(I R R_{i 0}-r_{0}^{f}\right)}_{\text {risk-premium effect }}
$$

where $l_{i t}=\frac{E_{i t}+D_{i t}}{E_{i t}}$ is a measure of market leverage at dat $t$. This formula is an exact decomposition. Its interpretation relies on the fact that even if the risk-premium asked by investors to bear systematic risk does not change, the risk-premium on equity should mechanically be affected by leverage. When values of assets drop, keeping debt unchanged, the exposure of equity to economic risk increases due to the increase in market leverage ${ }^{4}$. This effect is captured by the second term of Equation (3), which is equal to zero if leverage has not changed between 0 and $t$.

We implement this decomposition at the firm-level and after averaging at each date, we plot the results in Figure 11, in which the thin black line (total change in IRR) is the sum of the three thick gray lines. To compute the leverage variable $l_{i t}$, we use the firm's market capitalization at time $t$ and the book value of total debt as of end of 2019.

Figure 11 contains three main lessons: First, the Federal Reserve's actions have reduced the

\footnotetext{
${ }^{4}$ Formally, the cash flows generated by the firm's assets serve both debt and equity, leading to the ModiglianiMiller's "WACC formula": $r_{i t}^{A}-r_{t}^{f}=\frac{E_{i t}}{E_{i t}+D_{i t}}\left(r_{i t}-r_{t}^{f}\right)+\frac{D_{i t}}{E_{i t}+D_{i t}}\left(r_{i t}^{D}-r_{t}^{f}\right)$. The interpretation of our decomposition relies on assuming $\frac{D_{i t}}{E_{i t}+D_{i t}}\left(r_{i t}^{D}-r_{t}^{f}\right) \simeq 0$. Under this assumption, the economic risk-premium for holding assets' risk is $r_{i t}^{A}-r_{t}^{f}=\frac{E_{i t}}{E_{i t}+D_{i t}}\left(r_{i t}^{E}-r_{t}^{f}\right)$. The forward expectation of this term should not vary unless risk-premia on fundamental risk vary.
} 
Figure 11: Decomposition of IRR Changes over Time

The thin black line is total change in IRR. It is an average at each time $t$ over our sample of firms of $I R R_{i t}$ computed above. We decompose this line as the sum of the three thick gray lines, which represent effects coming from: (1) changes in the safe rate, (2) leverage and (3) changes in economic risk-premium. These effects are measured by taking the cross-sectional average of respectively: $\left(r_{t}^{f}-r_{0}^{f}\right),\left(1-\frac{l_{i 0}}{l_{i t}}\right)\left(I R R_{i t}-r_{t}^{f}\right)$, and $\frac{l_{i 0}}{l_{t}}\left(I R R_{i t}-r_{t}^{f}\right)-\left(I R R_{i 0}-r_{0}^{f}\right)$, in line with Equation 3. Firm leverage at time $t$ is based on equity values retreived from CRSP and the book value of debt at the end of 2019 from Compustat.

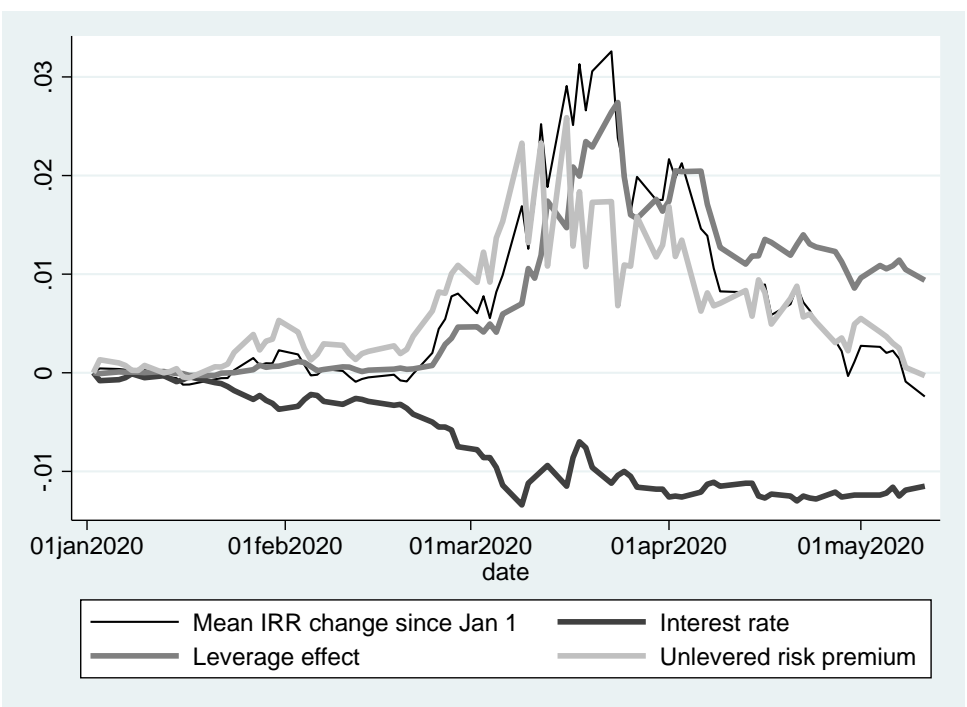

IRR by about 100bp via the safe rate of return. Second, the increase in unlevered asset risk premium has been temporary: By mid-May, the unlevered premium has returned to its pre-crisis level. Third, the leverage effect is quantitatively big, and contributes to all of the risk premium effect. Overall, in mid May, the increase in risl due to the leverage effect was entirely offset by the reduction in interest rates.

Of course, these estimates are vulnerable to the fact that we assume that debt is safe, which is not true during this period. We will include this adjustment in future work.

\subsection{Cross-sectional Variation in Discount Rates}

We find that the security market line implied by the cross section of discount rates is quite flat and variable, as is well known (Fama and French, 2004). In Appendix Figure A.6, we take the panel of firm-level discount rates, and regress the cross-section, every date, on firm-level betas supplied by WRDS. The graph makes clear that the SML is lower than what the CAPM implies. It went up and then back down.

There is also considerable cross-industry heterogeneity. In Appendix Figure A.7, we report the variation in discount rates across sectors: Energy and Real estate are the most impacted (real estate discount rate goes up from $15 \%$ to nearly 25\%). Information Technology goes up very 
slightly from 8 to $9 \%$. Financials are in between, from 13 to $16 \%$.

\subsection{Decomposition of Returns During the COVID Crisis: Discount rates vs EPS forecasts}

In this last section, we try to appraise the share of cross-section variation in returns that comes from EPS forecast revisions, vs discount rates.

We do this using the Campbell-Shiller decomposition (Campbell, 2017). It allows us to write down prices as a function of dividend expectations and returns expectations where $t$ is in years:

$$
p_{t}=\frac{k}{1-\rho}+(1-\rho) \sum_{j \geqslant 0} \rho^{j} E_{t} d_{t+1+j}-\sum_{j \geqslant 0} \rho^{j} E_{t} r_{t+1+j}
$$

so that log returns (between two consecutive dates excluding dividend payout) write:

$$
r_{t}=(1-\rho) \sum_{j \geqslant 0} \rho^{j} \mathbb{R}_{t} d_{t+1+j}-\sum_{j \geqslant 0} \rho^{j} \mathbb{R}_{t} r_{t+1+j}
$$

where $\mathbb{R}_{t} \equiv E_{t}-E_{s}$ is the revision operator between two consecutive dates (in our data, two consecutive days).

Assume that term structure of expected returns follows an AR1 process $E_{t} r_{t+j+1}=r_{j}^{f}+\mu+$ $\left(\mu_{t}-\mu\right) \phi^{j} \cdot r_{j}^{f}$ is the safe rate of return at horizon $j$. The revision of expected returns becomes:

$$
\mathbb{R}_{t} r_{t+1+j}=\Delta r_{j}^{f}+\phi^{j} \Delta \mu_{t}
$$

where $\Delta \mu_{t}$ is the change in expected next year equity returns. To simplify the algebra - though it is not necessary for the analysis, we assume here that the term structure of the revision of safe returns is flat: $\Delta r_{j}^{f}=\Delta r^{f}$. In the beginning of 2020, the 3-month US Treasury bill and the 10 year Treasury have both decreased by $1.50 \mathrm{ppt}$.

Thus, the return of firm $i$ follows (adding firm subscripts):

$$
r_{i t}=(1-\rho) \sum_{s \geqslant 0} \rho^{s} \mathbb{R}_{t} d_{i t+1+s}-\frac{1}{1-\rho \phi} \Delta \mu_{i t}-\frac{1}{1-\rho} \Delta r^{f}
$$

where $\rho=\frac{1}{1+e^{d-p}}$ and $\overline{d-p}$ is the mean log dividend yield. We assume $\rho$ and $\phi$ are the same for all stocks, but this first pass could be easily extended.

We run this regression in Table 1 . We define as sum of revisions for date $d$ and firm $i$ : 


$$
\begin{aligned}
\operatorname{Rev}_{i d} & =\sum_{h=2020}^{2022} \rho_{i}^{h-2020}\left(\log F_{d} E P S_{i h}-\log F_{d-1} E P S_{i h}\right) \\
& +\frac{\rho_{i}^{2}}{1-\rho_{i}}\left(\log F_{d} E P S_{i 2022}-\log F_{d-1} E P S_{i 2022}\right)
\end{aligned}
$$

which implicitly assumes that there is no revision in earnings growth beyond 2022. This assumption is supported by evidence from Figure 3. To simplify the exercise, we assume that $\rho_{i}=\rho=.96$ which is consistent with a $\mathrm{P} / \mathrm{D}$ ratio of about 25 .

We also compute a risk premium measure as the internal rates of returns obtained from solving Equation (2). This methodology, described in detail in the previous Section, assumes a flat termstructure while the current decomposition allows for mean reversion in risk premium $(\phi<1)$. We will work on making the two approaches more consistent in future research.

Table 1: Cross-Sectional Regressions

\begin{tabular}{lcccc}
\hline \hline \multicolumn{5}{c}{ cumulative daily log returns since Jan 1 } \\
& Week 9 & Week 9 & Week 14 & Week 14 \\
\hline \multirow{2}{*}{$R e v_{i d}$} & $.017^{* * *}$ & $.025^{* * *}$ & $.035^{* * *}$ & $.033^{* * *}$ \\
& $(5)$ & $(13)$ & $(8.8)$ & $(19)$ \\
$\Delta \mu_{i d}$ & & $-8.6^{* * *}$ & & $-8.4^{* * *}$ \\
& & $(-16)$ & & $(-27)$ \\
Constant & $-.08^{* * *}$ & $-.016^{* * *}$ & $-.23^{* * *}$ & $-.072^{* * *}$ \\
& $(-16)$ & $(-4.1)$ & $(-21)$ & $(-11)$ \\
$\mathrm{N}$ & 3071 & 2988 & 2611 & 2510 \\
$\mathrm{r} 2$ & .077 & .75 & .15 & .82 \\
& & & & \\
\hline
\end{tabular}

Note: We cluster error terms within observations of the same firm.

The first key lesson of this Table is that the cross-section of cumulative reaction to the crisis is mostly explained by discount rate. Focusing on EPS forecast revisions only, we only explain about $10 \%$ of the variation.

The second key lesson is that the model is sensitive, but not enough, to discount rate shocks. One possible explanation is that expected returns are badly measured. A second explanation is that $\phi<1$, i.e. that discount rate shocks are expected to mean revert at long horizon. Combining the coefficient on $\Delta \mu_{i d}$ and the coefficient on $\operatorname{Rev}_{i d}$, we can back out $\rho$ and $\phi$. Looking at the regression in week 14 for instance, we obtain $\rho=.965$ (which corresponds to a mean $\mathrm{D} / \mathrm{P}$ ratio of about 
$3.5 \%$ ), and $\phi-.92$, which corresponds to a persistent, but not perfectly flat, risk premium. We will study the implication of mean-reverting equity risk premium for valuation in future research (see Ang and Liu (2004)).

\section{Conclusion}

Firm-level analysts' consensus forecasts have been sluggishly revised down over March, April and May 2020 before leveling off. Analysts expect a long-lasting impact of the crisis: Even at long horizon, forecasts have been negatively impacted. Overall, assuming a constant discount rate, downward revisions are consistent with a mean average return of $-12 \%$, very close to the observed fall in equities. The actual discount rate started at $10 \%$ before the crisis, went all the way up to $13 \%$ in late March, back down to $10 \%$ in mid-May. This stability of the discount rate comes from an increase in the equity premium of about 1ppt, fully offset by a reduction in interest rates by 1 ppt over the period. We also observe that the entirety of the risk premium increase comes from the leverage effect: Adverse news increase the cost of equity. Unlevered asset risk premium only increased temporarily. 


\section{References}

Abarbanell, Jeffery S and Reuven Lehavy, "Letting the tail wag the dog: The debate over GAAP versus street earnings revisited," Contemporary Accounting Research, 2007, 24 (3), 675723.

- and Victor L Bernard, "Tests of analysts' overreaction/underreaction to earnings information as an explanation for anomalous stock price behavior," The Journal of Finance, 1992, 47 (3), 1181-1207.

Albuquerque, Rui A, Yrjo Koskinen, Shuai Yang, and Chendi Zhang, "Love in the Time of COVID-19: The Resiliency of Environmental and Social Stocks," Available at SSRN 3583611, 2020 .

Alfaro, Laura, Anusha Chari, Andrew N Greenland, and Peter K Schott, "Aggregate and firm-level stock returns during pandemics, in real time," Technical Report, National Bureau of Economic Research 2020.

Ang, Andrew and Jun Liu, "How to Discount Cash-flows with Time-Varying Expected Returns," Journal of Finance, 2004.

Bordalo, Pedro, Nicola Gennaioli, Rafael Laporta, and Andrei Shleifer, "Diagnostic Expectations and Stock Returns," 2018.

Bouchaud, Jean-Philippe, Philipp Krueger, Augustin Landier, and David Thesmar, "Sticky expectations and the profitability anomaly," The Journal of Finance, 2019, 74 (2), 639-674.

Campbell, John, Financial Decisions and Markets, Princeton University Press, 2017.

Cowen, Amanda, Boris Groysberg, and Paul Healy, "Which types of analyst firms are more optimistic?," Journal of Accounting and Economics, 2006, 41 (1-2), 119-146.

DeBondt, W. F. and R. H. Thaler, "Do security analysts overreact?," The American Economic Review, 1990, pp. 52-57.

Dechow, Patricia M, Amy P Hutton, and Richard G Sloan, "The relation between analysts' forecasts of long-term earnings growth and stock price performance following equity offerings," Contemporary Accounting Research, 2000, 17 (1), 1-32.

Ding, Wenzhi, Ross Levine, Chen Lin, and Wensi Xie, "Corporate Immunity to the COVID-19 Pandemic," Technical Report 2020. 
Dreman, David N and Michael A Berry, "Analyst forecasting errors and their implications for security analysis," Financial Analysts Journal, 1995, 51 (3), 30-41.

Fama, Eugene and Kenneth French, "The Capital Asset Pricing Model: Theory and Evidence," Journal of Economic Perspectives, 2004.

Gormsen, Niels and Ralph Koijen, "How to Interpret Financial Market Movements to Predict the Impact of Coronavirus on GDP," Technical Report 2020.

Hong, Harrison and Jeffrey D Kubik, "Analyzing the analysts: Career concerns and biased earnings forecasts," Journal of Finance, 2003, pp. 313-351.

Kadan, Ohad, Leonardo Madureira, Rong Wang, and Tzachi Zach, "Conflicts of interest and stock recommendations: The effects of the global settlement and related regulations," The Review of Financial Studies, 2008, 22 (10), 4189-4217.

Lakonishok, Josef, Andrei Shleifer, and Robert Vishny, "Contrarian Investment, Extrapolation and Risk," Journal of Finance, 1994, 49 (5), 1541-1578.

Laporta, Rafael, "Expectations and the Cross-Section of Stock Returns," Journal of Finance, 1996, 51 (5), 1715-1742.

Loh, Roger K and René M Stulz, "Is Sell-Side Research More Valuable in Bad Times?," The Journal of Finance, 2018, 73 (3), 959-1013.

Ma, Yueran, Tiziano Ropele, David Sraer, and David Thesmar, "A Quantitative Analysis of Distortions in Managerial Forecasts," Technical Report 2020.

Michaely, Roni and Kent L Womack, "Conflict of interest and the credibility of underwriter analyst recommendations," The Review of Financial Studies, 1999, 12 (4), 653-686.

Ramelli, Stefano and Alexander F Wagner, "Feverish stock price reactions to covid-19," 2020 .

Shiller, Robert, "Do Stock Prices Move Too Much to be Justified by Subsequent Changes in Dividends?," 1981. 


\section{A Appendix Figures}

Figure A.1: Mean analyst forecast error since 1990

We use IBES for the 1,000 largest firms by stock market capitalization every year. For each firm, we compute the consensus forecast error as the difference between median EPS forecast and realized EPS, normalized by median forecast. We ensure that the median forecast is positive, and trim outliers more than 5 IQR away from the median. We compute the mean error across all firms over periods of 5 years. A positive value indicates ex post optimism. We implement this exercise for 1,2 and 3 year horizon forecasts.

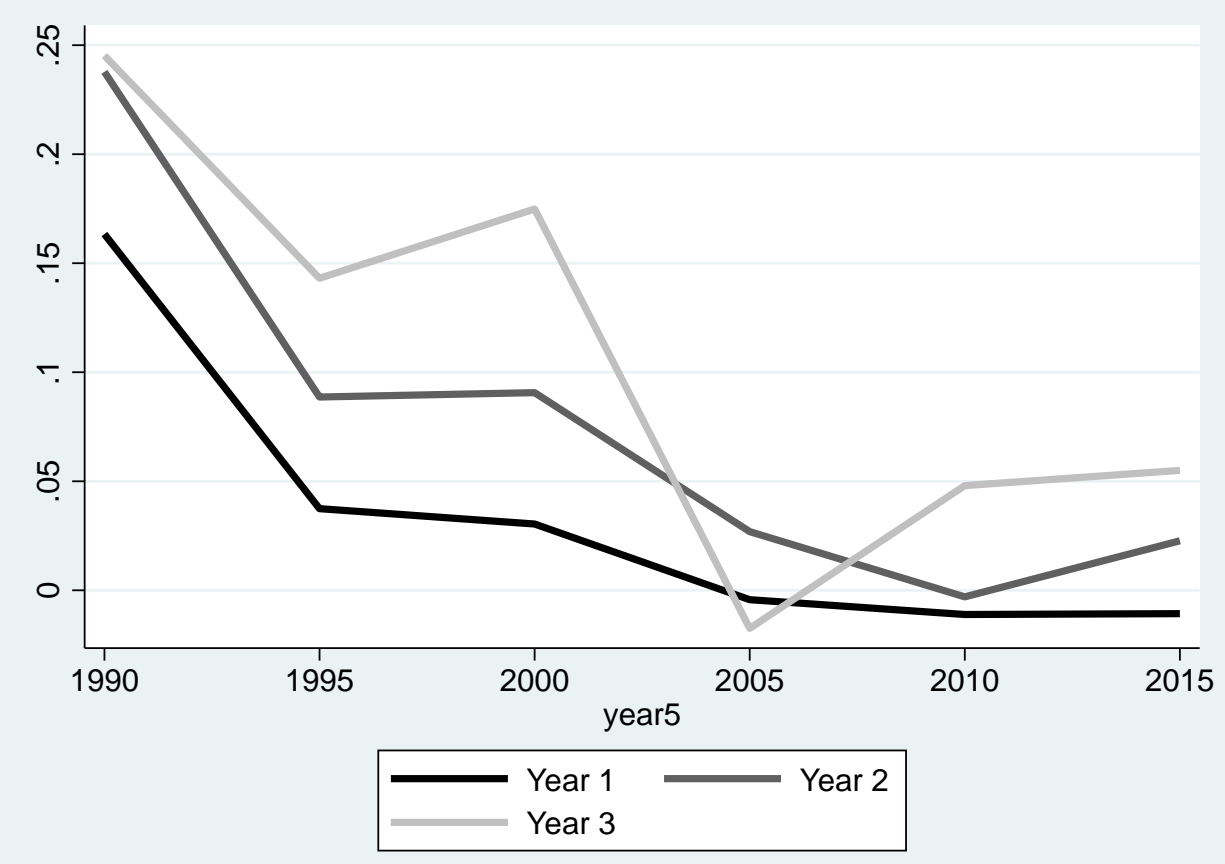


Figure A.2: Evolution of Analyst Forecast Errors

Around the Lehman Bankruptcy

We focus on firms with whose fiscal year ends in dec 31. For each firm, each month and each horizon we compute the difference between the median consensus forecast and actual realization, normalized by EPS in 2007. We impose that 2007 EPS is positive and trim outliers. We do not report 2008 FY forecast, since FY 2008 was largely completed when Lehman Brothers went bankrupt (so forecasts were not much revised). Reading: In September 2008, analyst EPS forecast for 2009/2010 were about $60 \%$ higher than the ex post realization.

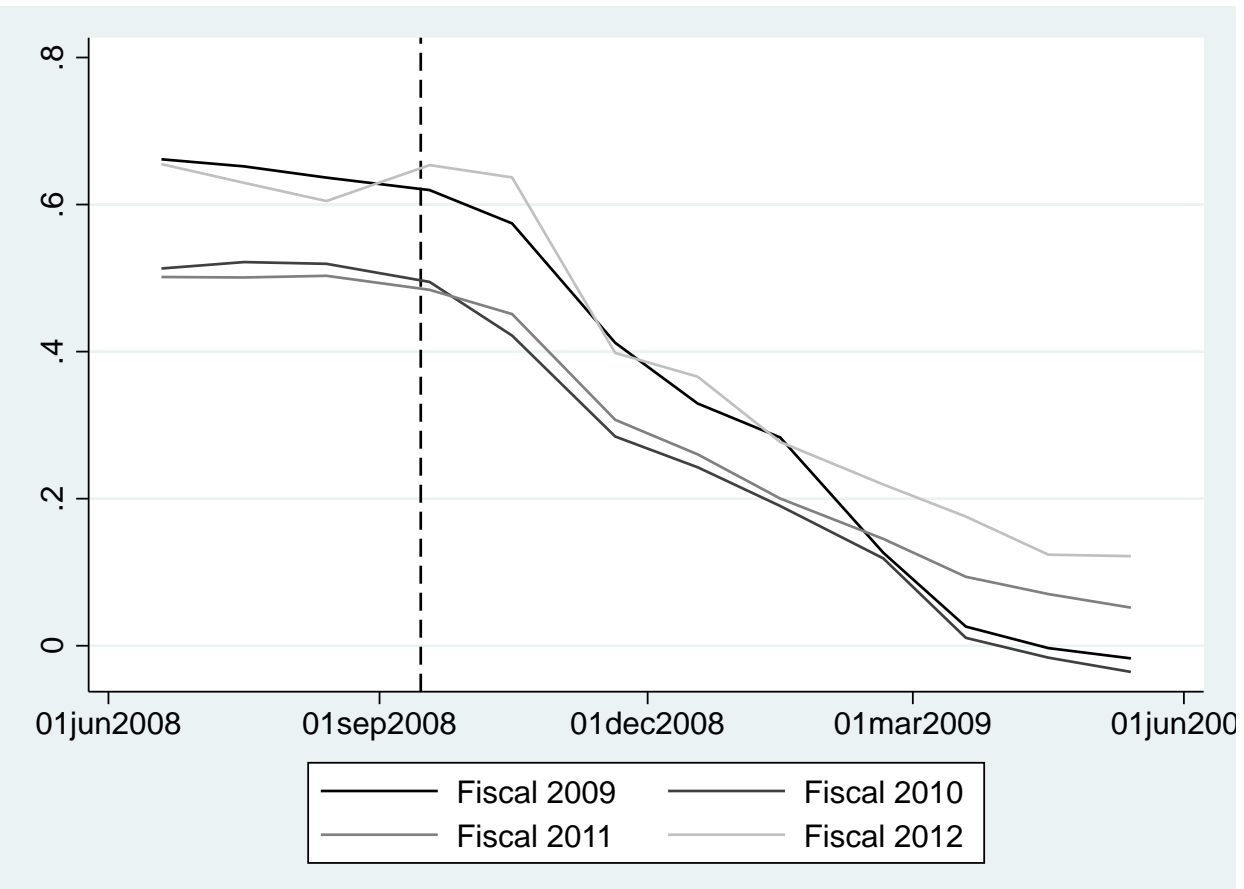


Figure A.3: Distribution of Implied Discount Rates

For each firm, at each date, we compute the internal rate of return from Equation (2), which uses as inputs the current stock price as well as the term structure of EPS forecasts. This chart shows the distribution of such IRRs for the first date in our panel, i.e. jan 2, 2020. We exclude the less than $1 \%$ of observations for which the algorithm failed to find a solution below $30 \%$.

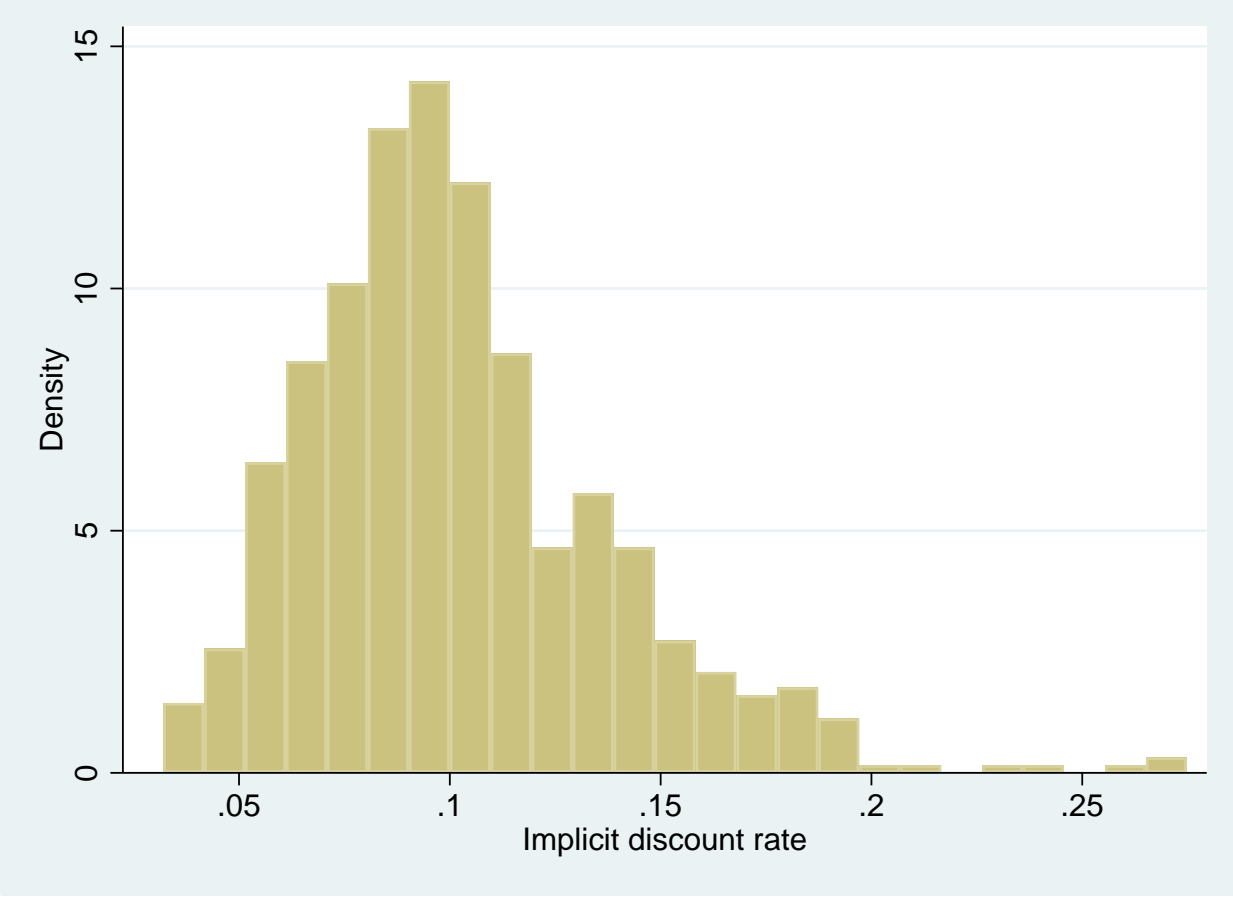


Figure A.4: Forecast implied cumulative market return

as a function of $r$

In this chart, we change the discount rate with which we estimate the PV of each stock using formula (1) which uses as inputs the daily term structure of forecasts. In main Figure 9, we use as discount rates a firm-specific IRR calculated on Jan 2, 2020, and an industry-level sales growth rate. In this Figure, we use a single $r$ for all firms, and vary it from $6 \%$ to $14 \%$. We set $g=4 \%$. The effect of $r$ on forecast-implied cumulative return since jan 2 is very small. The intuition is that we are looking at price changes, not price levels.

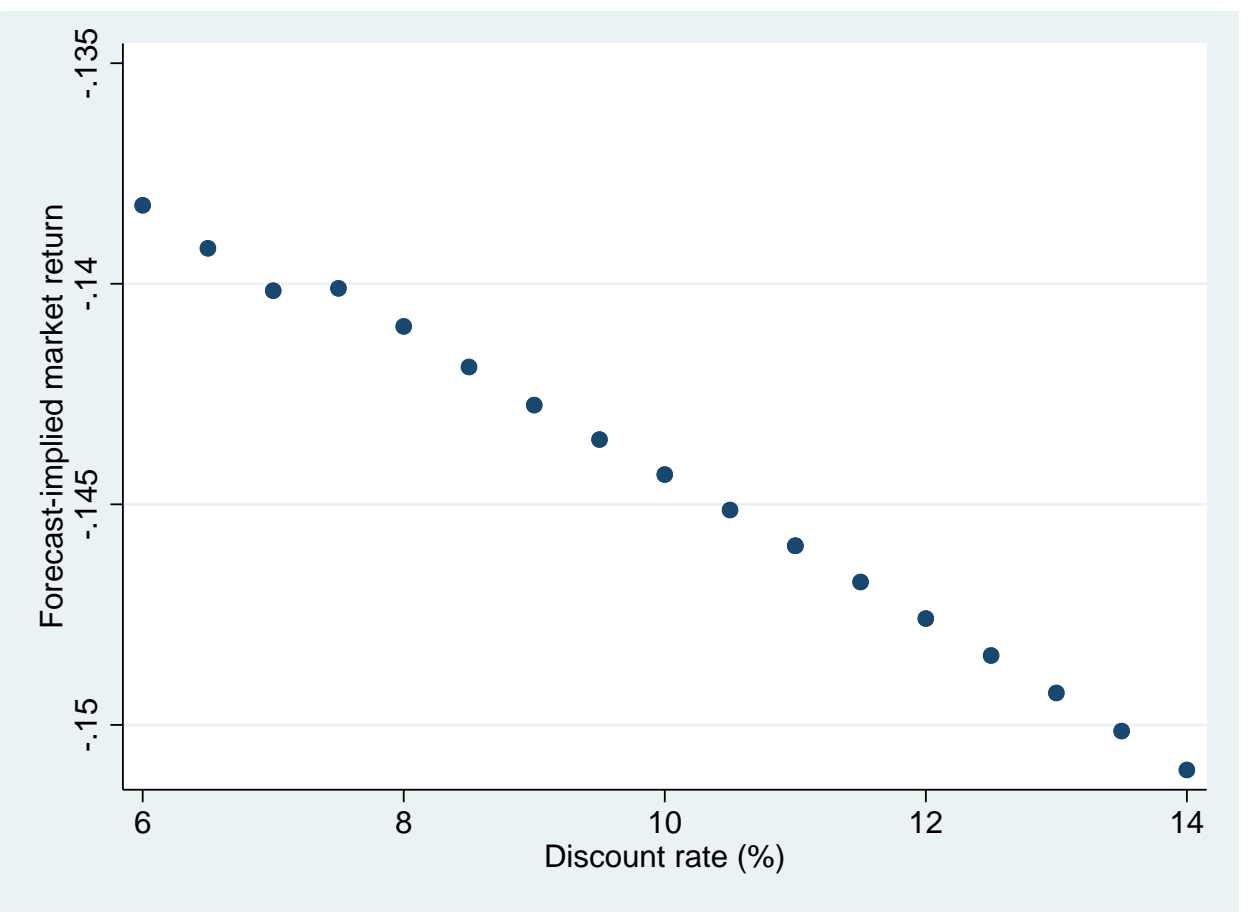


Figure A.5: Distribution of Implied Discount Rates

as a function of $g$

In this chart, we change the discount rate with which we estimate the PV of each stock using formula (1) which uses as inputs the daily term structure of forecasts. In main Figure 9, we use as discount rates a firm-specific IRR calculated on Jan 2, 2020, and an industry-level sales growth rate. In this Figure, we use a single $g$ for all firms, and vary it from $0 \%$ to $8 \%$. We set $r=10.5 \%$. The effect of $g$ on forecast-implied cumulative return since jan 2 is very small. The intuition is that we are looking at price changes, not price levels.

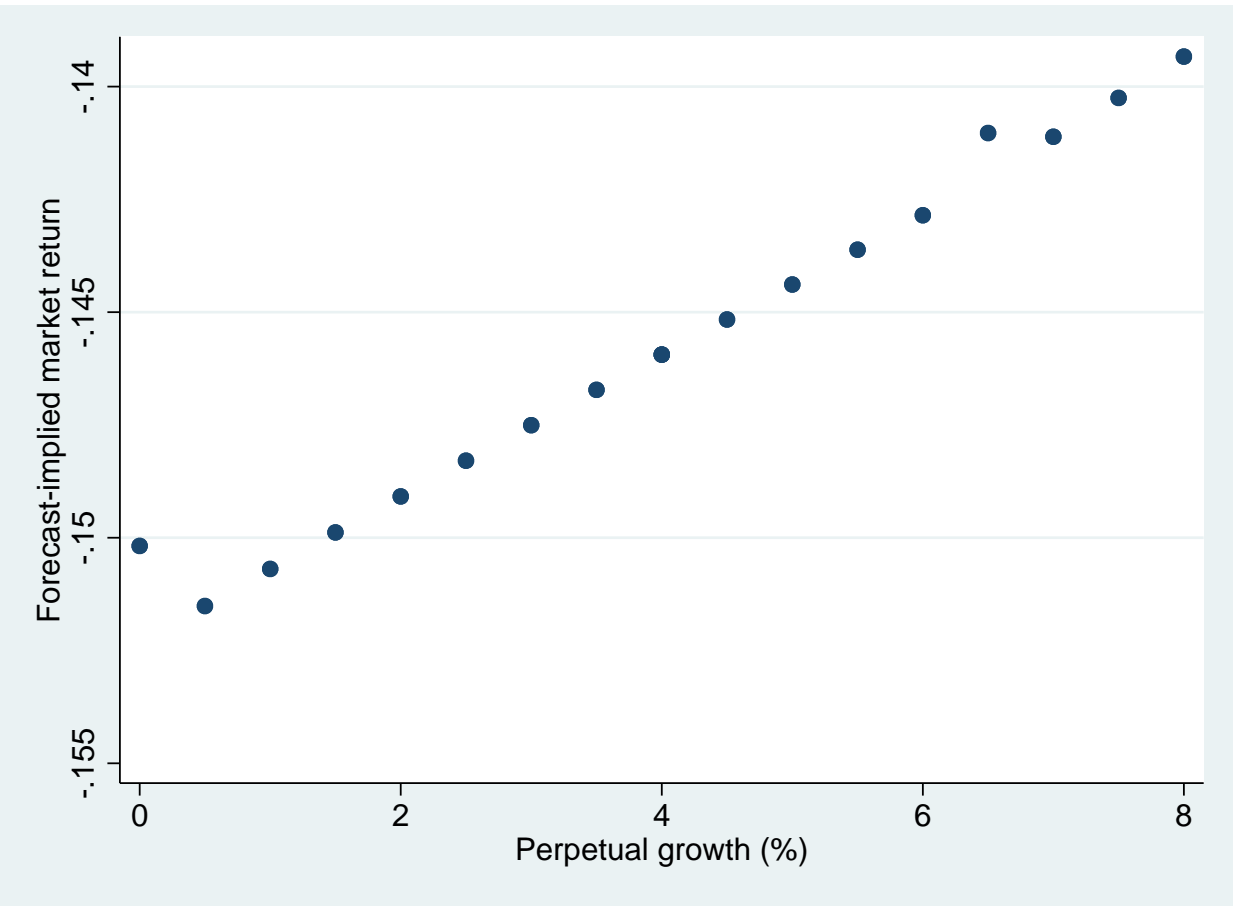


Figure A.6: Security Market Line

In this chart, we compute the security market line implicit in the cross-section discount rates and pre-crisis betas. For each date, we regress the cross-section of IRRs obtained from solving one equation (2) per firm, on the cross-section of dec 31, 2019 betas available from WRDS The slope of this line is shown in the chart.

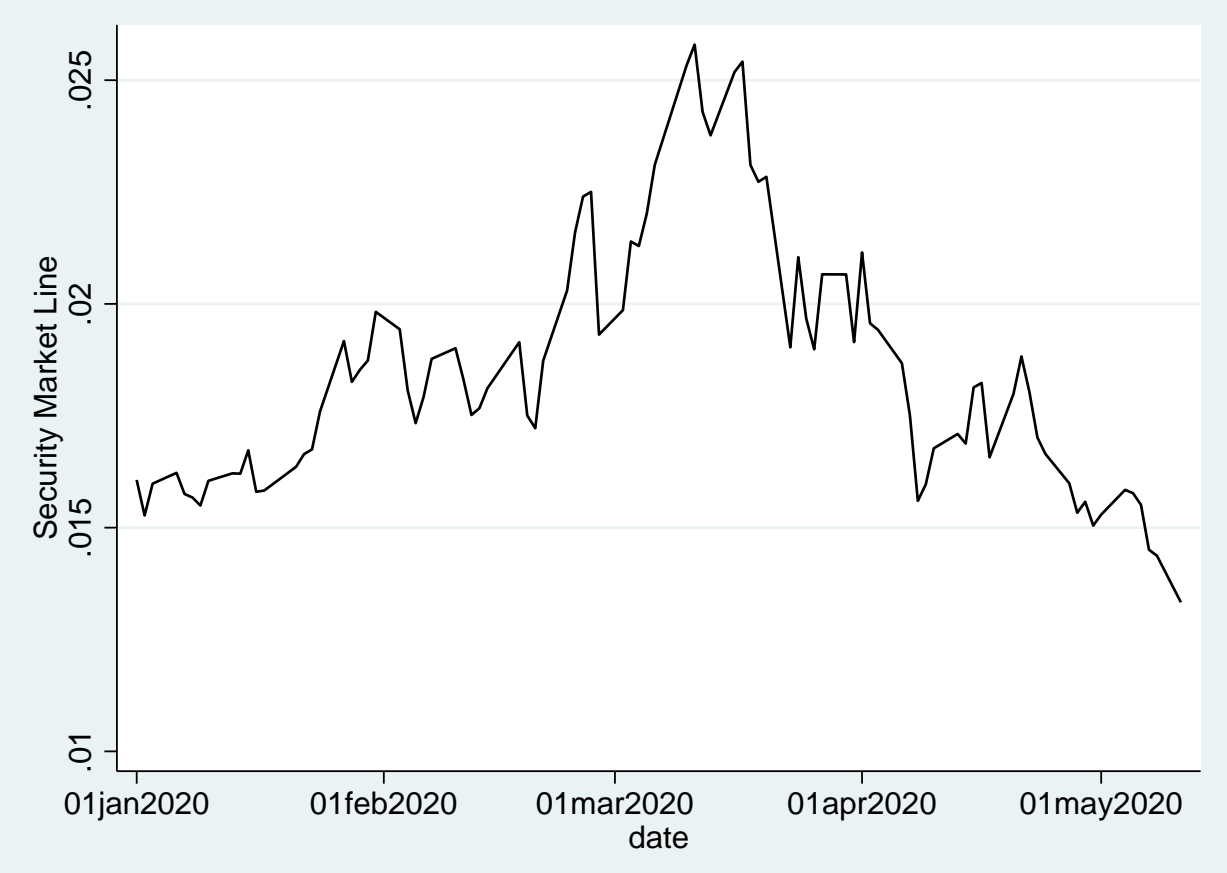


Figure A.7: Discount rate by Sector in Selected Industries

For each firm, at each date, we compute the internal rate of return from Equation (2), which uses as inputs the current stock price as well as the term structure of EPS forecasts. This chart shows the evolution of the discount rate for a selected sample of industries, using the GICS classification.

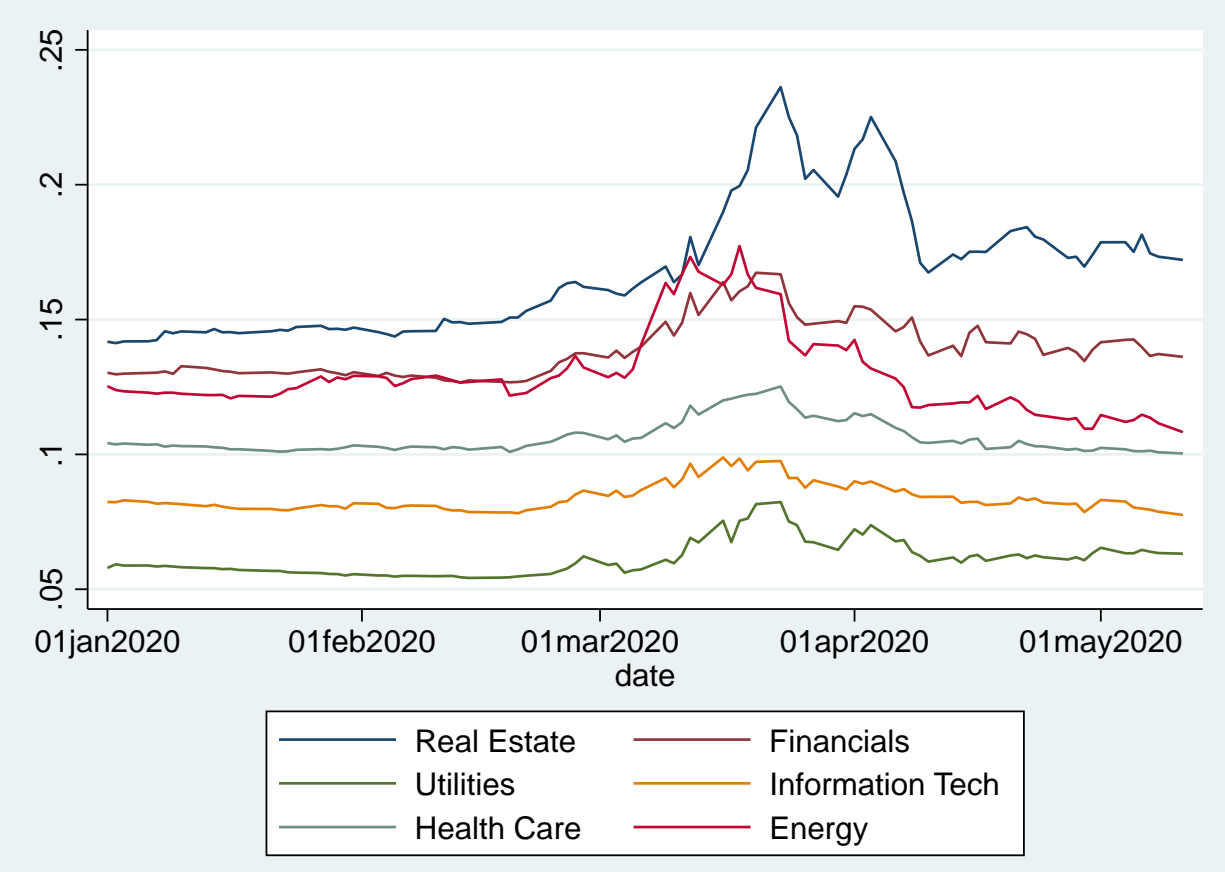

